\title{
Concordance to Guideline-recommended Statin Therapy: Real-world Evidence from India
}

\author{
Surendra Shamkant Borgharkar ${ }^{1,}$, , Soma Soumitra Das ${ }^{2}$ \\ ${ }^{1}$ Sun Pharmaceutical Industries Ltd., Mumbai, India \\ ${ }^{2}$ Covance Scientific Services \& Solutions Pvt. Ltd., Pune, India \\ Email address: \\ sborgharkar@gmail.com (S. S. Borgharkar), soma.das@covance.com (S. S. Das) \\ ${ }^{*}$ Corresponding author
}

\section{To cite this article:}

Surendra Shamkant Borgharkar, Soma Soumitra Das. Concordance to Guideline-recommended Statin Therapy: Real-world Evidence from India. American Journal of Health Research. Vol. 8, No. 3, 2020, pp. 18-25. doi: 10.11648/j.ajhr.20200803.11

Received: April 13,2020; Accepted: April 30, 2020; Published: May 28, 2020

\begin{abstract}
To evaluate concordance to the 2013 American College of Cardiology/American Heart Association (ACC/AHA) guideline on treatment of blood cholesterol for primary and secondary prevention of atherosclerotic cardiovascular disease (ASCVD) in India. Concordance to 2013 ACC/AHA guideline was assessed by retrospectively analyzing statin therapy prescribing practice as per ASCVD risk score in four statin-benefit groups in 23,295 patients aged 40-79 years from health facilities across India between 2017 and 2018. Mean ( \pm SD) age of patients was 58.9 ( \pm 9.2$)$ years; $62 \%$ were men; $60 \%$ $(\mathrm{n}=14,070)$ had clinical ASCVD. Among patients without ASCVD $(\mathrm{n}=7,122), 3.9 \%(\mathrm{n}=278)$ had low-density lipoproteincholesterol (LDL-C) $\geq 190 \mathrm{mg} / \mathrm{dL}, 94.0 \%(\mathrm{n}=6,694)$ had diabetes mellitus and 2.1\% $(\mathrm{n}=150)$ patients had 10-year ASCVD risk $\geq 7.5 \%$. Among 18,795 patients ( $81 \%$ ) eligible for high-intensity statins, only $34 \%$ were concordant whereas $63 \%$ were treated with moderate-intensity statins. Among 2,290 patients eligible for moderate-intensity statins, $76 \%$ were concordant and $18 \%$ received high-intensity statins. Among patients with ASCVD ( $<75$ years), 43\% received high-intensity statins, $55 \%$ received moderate-intensity statins, while $2 \%$ did not receive statins. Among patients with diabetes and ASCVD risk $<7.5 \%, 86 \%$ received moderate-intensity statins, but those with risk $>7.5 \%, 83 \%$ remained under-treated. Most patients (82\%) with LDLC $>190 \mathrm{mg} / \mathrm{dL}$ were prescribed with moderate-intensity statins. Most patients were receiving statins at dose non-concordant to 2013 ACC/AHA guideline, reflecting gaps in real-world practice of prescribing statins for primary and secondary prevention of ASCVD. Addressing care gaps and promoting compliance to optimize statin therapy will help reduce cardiovascular disease, especially in high-risk population among South Asians.
\end{abstract}

Keywords: Cardiovascular Disease, Statin Therapy, Real-world Evidence, Low-density Lipoprotein-Cholesterol, Cholesterol Guidelines

\section{Introduction}

Atherosclerotic cardiovascular diseases (ASCVDs) are the leading cause of mortality worldwide accounting for 18 million deaths every year [1]. Middle and low-income countries contribute to $75 \%$ of the global ASCVD burden [1]. ASCVD mortality has declined in high-income countries, while low-income countries, including India, continue to bear a high burden of cardiovascular events (6.43 events/1000 person-years) and case fatality rate $(17.3 \%)$ [2]. The agestandardized ASCVD death rate in India is higher than the global average [3]. ASCVDs contributed to about $28.1 \%$ of total deaths and $14.1 \%$ of disability-adjusted life years in India in 2016, which is nearly double of that observed two decades ago [4]. ASCVD trajectory is a critical challenge in India as the death rate is higher among people $<70$ years (53.4\%) [4].

Genetic susceptibility concomitant with factors such as aging population, thin-fat phenotype, higher prevalence of diabetes at a lower body mass index (BMI), dietary risks, and tobacco use act as catalysts for higher ASCVD risk among Indians [5]. Hypercholesterolemia (total cholesterol [TC] $\geq 200 \mathrm{mg} / \mathrm{dL}$ ) occurs in $25 \%-30 \%$ of urban and $15 \%-20 \%$ of rural Indian population [6]. The most common pattern of dyslipidemia consists of border-line high low-density 
lipoprotein cholesterol (LDL-C), low high-density lipoprotein cholesterol (HDL-C), and hypertriglyceridemia [6]. The Prospective Urban Rural Epidemiological (PURE) study highlighted the paradox of a high cardiovascular burden in India, despite having a lesser risk factor burden [2]. The PURE study concluded that ASCVD burden in highincome countries may have been mitigated by the control of risk factors through pharmacologic therapies and improved lifestyles. Primordial prevention by reducing the onset of risk factors such as smoking or obesity in healthy individuals and primary prevention by preventing the development of CVD in at-risk persons with diabetes, dyslipidemia, and hypertension are crucial alongside secondary prevention [7]. Early assessment of cardiovascular risk followed by a healthier lifestyle and appropriate pharmacological interventions is imperative for ASCVD management among Indians.

Different tools have been devised for ASCVD risk assessment such as the Framingham Risk Score, QRISK, and Joint British Society risk score; however, there is no specific tool designed for the South Asian population. The American College of Cardiology/American Heart Association (ACC/AHA) guidelines are the most widely used standards globally that predict the 10-year and lifetime ASCVD risks for an individual [8]. The 2013 ACC/AHA guidelines on the treatment of blood cholesterol to reduce ASCVD risk in adults identified four statin benefit groups for the primary and secondary prevention of ASCVD, namely patients with (1) clinical ASCVD, (2) LDL-C $\geq 190 \mathrm{mg} / \mathrm{dL}$, (3) diabetes and LDL-C 70-189 mg/dL, and (4) estimated 10-year ASCVD risk $\geq 7.5 \%$. The guideline highlighted that addressing insufficient response to lipid reduction by optimizing statin therapy intensity or change in therapy is crucial for ASCVD risk reduction. The 2018 ACC/AHA guideline on management of blood cholesterol is an update to the 2013 guideline and emphasizes on a more intensive approach for reducing risk of ASCVD.

Management of ASCVD presents unique challenges in India such as inconsistencies among physicians regarding ASCVD risk estimation and suboptimal prescription of statins. A multisite prescription study in India demonstrated that statins are prescribed in only half of clinic-based patients [9]. Real-world data on ASCVD risk and the prescription pattern of statin therapy among Indian population are scarce. This study was conducted to determine and evaluate the concordance to statin therapy per the ASCVD risk score and recommendations of the 2013 ACC/AHA guideline for cholesterol management for the primary and secondary prevention of ASCVD in India.

\section{Research Design and Methodology}

\subsection{Study Design and Settings}

This cross-sectional study was conducted at 2,980 private healthcare facilities across India between 2017 and 2018. Protocol-defined data were retrospectively transcribed on the
MORE (measurement of ASCVD risk parameters in Indian patients eligible for statin treatment) data collection form by healthcare providers (physicians, diabetologists, and cardiologists) based on the available medical records. Patients of either sex, aged 40-79 years, irrespective of their ASCVD status were included. Data of patients $<40$ years of age and those with missing or erroneous values were excluded. The study included retrospective data collection from anonymous patient records; hence, it was exempted from ethical clearance.

\subsection{Study Outcomes}

The primary outcome was to evaluate the proportion of patients' receiving statin therapy in concordance with the 2013 ACC/AHA guideline.

\subsection{Operational Definitions}

Clinical ASCVD was defined as acute coronary syndromes, a history of myocardial infarction (MI), stable or unstable angina, coronary or other arterial revascularization, stroke, transient ischemic attack, or peripheral arterial disease [8]. The10-year risk of developing ASCVD was calculated using the ACC/AHA risk estimator: low (0\%-5\%), moderate (5\%-7.5\%), and high ( $\geq 7.5 \%)$. Statin therapy was classified as high-intensity (atorvastatin $40-80 \mathrm{mg}$ and rosuvastatin 20 $40 \mathrm{mg}$ ), moderate-intensity (atorvastatin 10-20 mg, rosuvastatin $5-10 \mathrm{mg}$, simvastatin $20-40 \mathrm{mg}$, and pitavastatin 2-4 mg), and low-intensity (simvastatin $10 \mathrm{mg}$ ). The 2013 ACC/AHA guidelines were followed to ascertain the eligibility of patients for each statin therapy group: highintensity statins (clinical ASCVD patients $<75$ years, adults $>21$ years with $\mathrm{LDL} \geq 190 \mathrm{mg} / \mathrm{dL}$ and patients with diabetes having ASCVD risk $\geq 7.5 \%$ ) and moderate-intensity statins (older ASCVD patients $>75$ years, patients with diabetes having ASCVD risk $\geq 7.5 \%$, and patients with ASCVD risk $>5 \%$ to $<7.5 \%$ ). The guidelines recommend submaximal statin therapy to reduce ASCVD risk in patients unable to tolerate moderate- or high-intensity statin therapy. Glycemic control was defined as controlled (glycated hemoglobin [HbA1c] $<7 \%$ ) or uncontrolled (HbA1c $\geq 7 \%$ ) [10]. BMI was categorized as normal $\left(18-22.9 \mathrm{~kg} / \mathrm{m}^{2}\right)$, overweight (23-24.9 kg/m $\left.{ }^{2}\right)$, and obese $\left(\geq 25 \mathrm{~kg} / \mathrm{m}^{2}\right)$ [11]. Blood pressure (BP in $\mathrm{mmHg}$ ) was categorized as prehypertension (systolic BP $[\mathrm{SBP}]=120-139$ or diastolic BP $[\mathrm{DBP}]=80-89)$, stage 1 hypertension $(\mathrm{SBP}=140-159$ or $\mathrm{DBP}=90-99)$, stage 2 hypertension $(\mathrm{SBP} \geq 160$ or $\mathrm{DBP} \geq 100)$ [12]. Dyslipidemia was classified according to National Cholesterol Education Program Adult Treatment Panel III guidelines as (a) TC: desirable $(<200 \mathrm{mg} / \mathrm{dL})$, borderline high (200239 mg/dL) and high ( $\geq 240 \mathrm{mg} / \mathrm{dL})$; (b) HDL: men, low $(<40 \mathrm{mg} / \mathrm{dL})$, high $(\geq 40 \mathrm{mg} / \mathrm{dL})$ and women, low $(<50$ $\mathrm{mg} / \mathrm{dL}$ ), high ( $\geq 50 \mathrm{mg} / \mathrm{dL})$; (c) LDL: optimal ( $<100 \mathrm{mg} / \mathrm{dL})$, near optimal/above optimal (100-129 mg/dL), borderline high (130-159 mg/dL), high (160189 mg/dL), very high $(>190 \mathrm{mg} / \mathrm{dL})$; and $(\mathrm{d})$ triglycerides: normal $(<150 \mathrm{mg} / \mathrm{dL})$, borderline-high (150-199 mg/dL), and high (200-499 mg/dL) 
[13].

\subsection{Data Collection and Statistical Analysis}

Data collection included patient demographics, clinical history (including diabetes), ASCVD history, tobacco history, anthropometric measures, vital signs, physical examination, antihypertensive treatment, and statin pharmacotherapy. The latest available laboratory results for $\mathrm{HbA1c}, \mathrm{TC}$, LDL-C, HDL-C, and triglycerides were recorded. Summary statistics for quantitative variables included the frequency distribution, mean, and standard deviation (SD). Results are expressed as absolute values and percentages. Patients receiving statins at the recommended intensity were classified as concordant. This was primarily a descriptive study designed to determine the proportion of patients' receiving statin therapy in concordance with the 2013 ACC/AHA guideline. Descriptive analyses including cross-tabulations were performed for estimating the proportion of patients who were prescribed statin therapy in concordance with the guidelines. Statistical analyses were performed using SAS version 9.4.

\section{Results}

\subsection{Demographic and Clinical Profile}

A total of 23,295 records between 2017 and 2018 were found eligible for inclusion in the study. Table 1 summarizes the demographic and clinical characteristics of the study population.

Table 1. Demographic and clinical profile in the overall population $(N=23,295)$.

\begin{tabular}{|c|c|c|}
\hline & $\mathbf{n}$ & $\%$ \\
\hline Age (Mean \pm SD) & $58.89 \pm 9.21$ & \\
\hline $40-75$ years & 22540 & 96.8 \\
\hline$>75$ years & 755 & 3.2 \\
\hline \multicolumn{3}{|l|}{ Gender } \\
\hline Male & 14546 & 62.4 \\
\hline Female & 8749 & 37.6 \\
\hline Current tobacco user & 8256 & 35.4 \\
\hline Body mass index* $($ Mean \pm SD $)$ & $26.57 \pm 3.45 \mathrm{~kg} / \mathrm{m}^{2}$ & \\
\hline Normal $\left(18-22.9 \mathrm{~kg} / \mathrm{m}^{2}\right)$ & 2083 & 8.9 \\
\hline Overweight $\left(23-24.9 \mathrm{~kg} / \mathrm{m}^{2}\right)$ & 3030 & 13.0 \\
\hline Obesity $(\geq 25$ kg/m²) & 11155 & 47.9 \\
\hline Total Cholesterol $(\mathrm{TC}) \dagger($ Mean $\pm \mathrm{SD})$ & $197.11 \pm 25.73$ & \\
\hline Desirable $(<200 \mathrm{mg} / \mathrm{dL})$ & 12489 & 53.6 \\
\hline Borderline high $(200-239 \mathrm{mg} / \mathrm{dL})$ & 8897 & 38.2 \\
\hline High $(\geq 240 \mathrm{mg} / \mathrm{dL})$ & 1909 & 8.2 \\
\hline High density Lipoprotein $(\mathrm{HDL}) \ddagger($ Mean $\pm \mathrm{SD})$ & $39.49 \pm 8.34$ & \\
\hline Low $(<40 \mathrm{mg} / \mathrm{dl})$ - Male & 7120 & 30.6 \\
\hline$(\geq 40 \mathrm{mg} / \mathrm{dl})-$ Male & 7426 & 31.8 \\
\hline Low $(<50 \mathrm{mg} / \mathrm{dl})$-Female & 7725 & 33.2 \\
\hline$(\geq 50 \mathrm{mg} / \mathrm{dl})$ - Female & 1024 & 4.4 \\
\hline Low density Lipoprotein (LDL) $\S($ Mean \pm SD) & $126.07 \pm 32.47$ & \\
\hline Optimal $(<100 \mathrm{mg} / \mathrm{dl})$ & 5171 & 22.2 \\
\hline Near optimal/above optimal (100-129 mg/dL) & 8091 & 34.7 \\
\hline Borderline high $(130-159 \mathrm{mg} / \mathrm{dL})$ & 5219 & 22.4 \\
\hline $\operatorname{High}(160-189 \mathrm{mg} / \mathrm{dL})$ & 3622 & 15.5 \\
\hline Very high $(\geq 190 \mathrm{mg} / \mathrm{dL})$ & 1005 & 4.3 \\
\hline Triglyceride (Mean \pm SD) $\|$ & $186.23 \pm 60.20$ & \\
\hline $\operatorname{Normal}(<150 \mathrm{mg} / \mathrm{dL})$ & 6270 & 26.9 \\
\hline Borderline-high (150-199mg/dL) & 8791 & 37.7 \\
\hline High $(200-499 \mathrm{mg} / \mathrm{dL})$ & 8104 & 34.8 \\
\hline Diagnosed as Diabetic & 17452 & 74.9 \\
\hline Diagnosed as Hypertensive** & 18301 & 78.6 \\
\hline Anti-hypertensive treatment & 17384 & 94.9 \\
\hline
\end{tabular}

*BMI: Normal $\left(18-22.9 \mathrm{~kg} / \mathrm{m}^{2}\right)$, overweight $\left(2324.9 \mathrm{~kg} / \mathrm{m}^{2}\right)$, and obese $\left(\geq 25 \mathrm{~kg} / \mathrm{m}^{2}\right)$.

$\dagger$ TC: Desirable $(<200 \mathrm{mg} / \mathrm{dL})$, borderline high $(200-239 \mathrm{mg} / \mathrm{dL})$ and high $(\geq 240 \mathrm{mg} / \mathrm{dL})$.

$\$$ HDL: Men, low $(<40 \mathrm{mg} / \mathrm{dL})$, high $(\geq 40 \mathrm{mg} / \mathrm{dL})$ and women, low $(<50 \mathrm{mg} / \mathrm{dL})$, high $(\geq 50 \mathrm{mg} / \mathrm{dL})$

$\S$ LDL: Optimal (<100 mg/dL), near optimal/above optimal (100-129 mg/dL), borderline high (130-159 mg/dL), high (160-189 mg/dL), very high ( $\geq 190$ $\mathrm{mg} / \mathrm{dL})$.

||Triglycerides: Normal (<150 mg/dL), borderline-high (150-199 mg/dL), and high (200-499 mg/dL).

TGlycemic control: Glycated hemoglobin $[\mathrm{HbA} 1 \mathrm{c}]<7 \%$, uncontrolled (HbA1c $\geq 7 \%$ ).

**Blood pressure (mmHg): Prehypertension (systolic BP [SBP]=120-139 or diastolic BP [DBP]=80-89), stage 1 hypertension $(\mathrm{SBP}=140-159$ or DBP=90-99), stage 2 hypertension ( $\mathrm{SBP} \geq 160$ or $\mathrm{DBP} \geq 100$ ). 
The mean $( \pm \mathrm{SD})$ age of patients was $58.89 \pm 9.21$ years; most patients $(n=22,540,96.8 \%)$ were in the age group of $40-75$ years with male predominance $(n=14,546,62.4 \%)$. At the time of data collection, approximately one-third of the study population $(n=8,256,35.4 \%)$ were tobacco users. The mean BMI of patients was $26.57 \pm 3.45 \mathrm{~kg} / \mathrm{m}^{2}$ and almost half $(47.9 \%, n=11,155)$ of them were obese. About $78.6 \%$ $(\mathrm{n}=18,301)$ of patients were diagnosed as hypertensive, of which $94.9 \%(n=17,384)$ were receiving antihypertensive medications. Overall, $74.9 \%(n=17,452)$ of patients were diagnosed with diabetes mellitus. The mean TC level among the study population was $197.11 \pm 25.73 \mathrm{mg} / \mathrm{dL}$ while $46.4 \%(n=10,806)$ had TC $\geq 200 \mathrm{mg} / \mathrm{dL}$. Mean triglyceride level was $186.23 \pm 60.20 \mathrm{mg} / \mathrm{dL}$, and nearly three-fourths of patients $(72.5 \%, \mathrm{n}=16,895)$ had triglycerides $\geq 150 \mathrm{mg} / \mathrm{dL}$. Mean HDL-C level was $39.49 \pm 8.34 \mathrm{mg} / \mathrm{dL}$. Among the men, almost half $(\mathrm{n}=7,120 ; 48.9 \%)$ had low HDL-C $(<40$ $\mathrm{mg} / \mathrm{dL})$, while among women, $88.3 \%(\mathrm{n}=7,725)$ had low HDL-C $(<50 \mathrm{mg} / \mathrm{dL})$. The mean LDL-C level was $126.07 \pm 32.47 \mathrm{mg} / \mathrm{dL}$, only $22.2 \%$ had optimal LDL-C level $<100 \mathrm{mg} / \mathrm{dL}$ while $4.3 \%(\mathrm{n}=1,005)$ had LDL-C $\geq 190 \mathrm{mg} / \mathrm{dL}$. The prevalence of risk factors was highest among patients with ASCVD (tobacco use: $42 \%$, obesity: $46.7 \%$, diabetes: $73.6 \%$, hypertension: $84.9 \%$ ) while $96.0 \%$ were receiving antihypertensive medications (Table 2).

Table 2. Demographic and clinical characteristics of the study population according to the four statin benefit groups

\begin{tabular}{|c|c|c|c|c|}
\hline & \multirow{2}{*}{$\begin{array}{l}\text { Clinical ASCVD } \\
(\mathrm{N}=\mathbf{1 4 , 0 7 0 )}\end{array}$} & \multicolumn{3}{|c|}{ No clinical ASCVD $(\mathrm{N}=7122)$} \\
\hline & & $\begin{array}{l}\mathrm{LDL} \geq 190 \mathrm{mg} / \mathrm{dL}^{*} \\
(\mathrm{~N}=278)\end{array}$ & Diabetes $\uparrow(N=6,694)$ & $\begin{array}{l}\text { ASCVD Risk } \geq 7.5 \\
(\mathrm{~N}=150) \ddagger\end{array}$ \\
\hline \multicolumn{5}{|l|}{ Age $n(\%)$} \\
\hline $40-75$ years & $13,504(96.0)$ & $271(97.5)$ & $6,694(100)$ & $150(100)$ \\
\hline$>75$ years & $566(4.0)$ & $7(2.5)$ & - & - \\
\hline \multicolumn{5}{|l|}{ Gender n $(\%)$} \\
\hline Male & $9,291(66.0)$ & $159(57.2)$ & $3,809(56.9)$ & $126(84.0)$ \\
\hline Female & $4,779(34.0)$ & $119(42.8)$ & $2,885(43.1)$ & $24(16.0)$ \\
\hline Tobacco user $\mathrm{n}(\%)$ & $5,908(42.0)$ & $77(27.7)$ & $1,768(26.4)$ & $59(39.3)$ \\
\hline Body mass index (BMI) $\mathrm{kg} / \mathrm{m}^{2}($ mean $\pm \mathrm{SD})$ & $26.77 \pm 3.46$ & $26.34 \pm 3.89$ & $26.23 \pm 3.40$ & $26.04 \pm 2.48$ \\
\hline Total Cholesterol (TC) mg/dL (mean \pm SD) & $197.80 \pm 26.06$ & $214.20 \pm 25.51$ & $194.63 \pm 24.51$ & $202.57 \pm 25.08$ \\
\hline High density Lipoprotein (HDL) $\mathrm{mg} / \mathrm{dL}($ mean $\pm \mathrm{SD})$ & $38.88 \pm 8.60$ & $36.18 \pm 6.88$ & $40.20 \pm 7.75$ & $42.17 \pm 7.70$ \\
\hline Low density Lipoprotein (LDL) mg/dL (mean \pm SD) & $129.55 \pm 32.96$ & $193.53 \pm 3.39$ & $117.59 \pm 27.66$ & $120.18 \pm 23.92$ \\
\hline Triglycerides $\mathrm{mg} / \mathrm{dL}(\operatorname{mean} \pm \mathrm{SD})$ & $189.79 \pm 60.28$ & $208.10 \pm 61.66$ & $179.66 \pm 58.82$ & $202.67 \pm 70.70$ \\
\hline Diagnosed as Diabetic n (\%) & $10,353(73.6)$ & $188(67.6)$ & $6,694(100)$ & - \\
\hline Diagnosed as Hypertensive $\mathrm{n}(\%)$ & $11,942(84.9)$ & $183(65.8)$ & $4,860(72.6)$ & $79(52.7)$ \\
\hline Receiving antihypertensive treatment $\mathrm{n}(\%)$ & $11,417(95.6)$ & $174(95.0)$ & $4,512(92.8)$ & $69(87.3)$ \\
\hline
\end{tabular}

*Includes patients aged 21 years and older with $\mathrm{LDL} \geq 190 \mathrm{mg} / \mathrm{dL}$.

$\dagger$ Includes diabetic patients with age 40-75 years and LDL-C 70-189 mg/dL.

\$Includes patients 40-75 years without diabetes and ASCVD risk $\geq 7.5$.

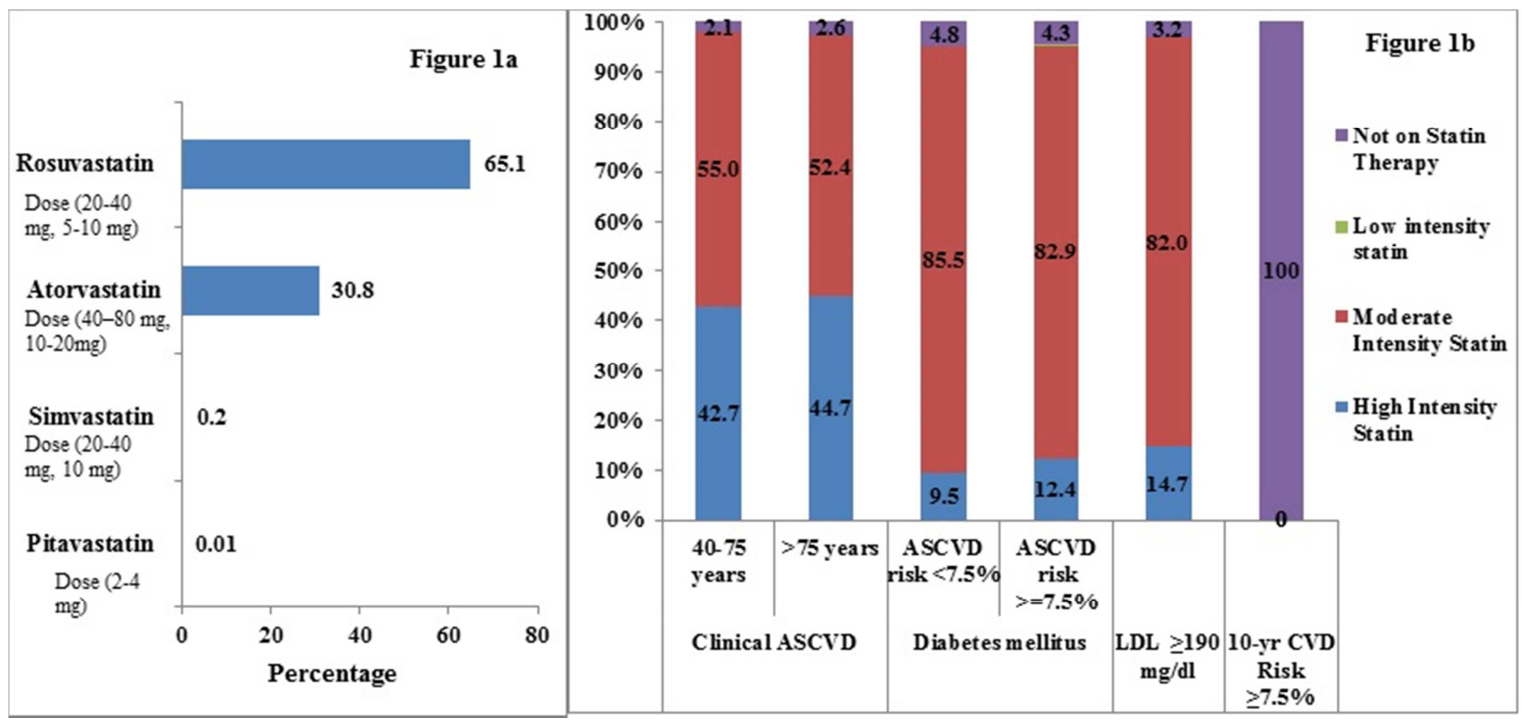

Figure 1. Distribution of statin therapy in the study population.

a Distribution of statin therapy in the study population.

b Distribution of statin therapy in the 4 statin benefit groups.

Patients with clinical ASCVD $n=14,070$ (age 40-75 years, $n=13,504$; age $>75$ years, $n=566$ ), patients with diabetes and ASCVD risk $<7.5 \% n=1681$, patients with diabetes and ASCVD risk $\geq 7.5 \% \mathrm{n}=5013, \mathrm{LDL}>190 \mathrm{mg} / \mathrm{dL} \mathrm{n}=278,10$-year ASCVD risk $\geq 7.5 \% \mathrm{n}=150$. 


\subsection{ASCVD Risk Scores}

Of the study population $(\mathrm{N}=23,295), 17.4 \%(\mathrm{n}=4,051)$ had a history of acute MI, 8.6\% $(\mathrm{n}=1,994)$ had stroke, while $17.2 \%$ $(\mathrm{n}=4,007)$ and $10.4 \%(\mathrm{n}=2,414)$ reported unstable and stable angina, respectively. Additionally, 7.3\% $(\mathrm{n}=1,694)$ had undergone arterial revascularization while $4.4 \%(n=1,025)$ had a history of peripheral arterial disease (data not shown). Overall, 78.8\% ( $\mathrm{n}=18,347)$ of patients had an ASCVD risk of $\geq 7.5 \%$, while $8.3 \%(\mathrm{n}=1,928)$ had a moderate risk of $5 \%-7.5 \%$. Among diabetes patients without ASCVD ( $\mathrm{n}=6,694), 74.9 \%$ $(\mathrm{n}=5,013)$ had a risk score of $\geq 7.5 \%$ while $9.9 \%(\mathrm{n}=664)$ had risk between $5 \%$ and $7.5 \%$.

\subsection{Statin Therapy}

The statin therapy in our study population was primarily comprised of rosuvastatin $(65.1 \%, \quad \mathrm{n}=15,168)$ and atorvastatin $(30.8 \%, \mathrm{n}=7,173)$; some patients were also prescribed pitavastatin $(\mathrm{n}=3)$ and simvastatin $(\mathrm{n}=35)$ as monotherapy or combination therapy. The proportion of individuals receiving moderate-intensity statins included atorvastatin $10-20 \mathrm{mg}(24.8 \%, \mathrm{n}=5,784)$, rosuvastatin $5-10$ $\mathrm{mg}(40.4 \%, \mathrm{n}=9,417)$, simvastatin $20-40 \mathrm{mg}(\mathrm{n}=4)$, and pitavastatin 2-4 mg $(\mathrm{n}=3)$, while those receiving highintensity statins included atorvastatin $40-80 \mathrm{mg}(6.0 \%$, $\mathrm{n}=1,387)$ and rosuvastatin $20-40 \mathrm{mg}(24.6 \%, \mathrm{n}=5,736)$ (Figure 1a).

\subsection{Concordance to Statin Intensity Per 2013 ACC/AHA Guidelines}

Of the patients eligible for treatment with high-intensity statins $(80.7 \%, \mathrm{n}=18,795)$, only $34.2 \%(\mathrm{n}=6,436)$ received high-intensity statin therapy (Table 3). Most patients (62.9\%, $\mathrm{n}=11,820)$ remained under-treated with moderate-intensity statins and a small proportion $(2.7 \%, \mathrm{n}=511)$ did not receive any statins.

Table 3. Statin eligibility in study population according to the 2013 ACC/AHA guideline

\begin{tabular}{|c|c|c|c|c|c|}
\hline \multirow[t]{2}{*}{$\begin{array}{l}\text { Recommend Statin Therapy Intensity } \\
\text { per ASCVD Risk }\end{array}$} & $\begin{array}{l}\text { High-intensity } \\
\text { Statins }\end{array}$ & $\begin{array}{l}\text { Moderate- } \\
\text { intensity } \\
\text { Statins }\end{array}$ & $\begin{array}{l}\text { Moderate- or } \\
\text { High-intensity } \\
\text { Statins }\end{array}$ & $\begin{array}{l}\text { Statins Initiated After } \\
\text { Physician Patient Dialogue } \\
\S\end{array}$ & Total \\
\hline & 18,795 & 2290 & 150 & 2060 & 23,295 \\
\hline \multicolumn{6}{|l|}{ Actual statin intensity } \\
\hline Received high-intensity* n (\%) & $6436(34.2)$ & $413(18.1)$ & 0 & $273(13.3)$ & $7122(30.6)$ \\
\hline Received moderate-intensity $\uparrow \mathrm{n}(\%)$ & $11,820(62.9)$ & $1735(75.8)$ & 0 & $1632(79.2)$ & $15,187(65.2)$ \\
\hline Received low-intensity $\ddagger \mathrm{n}(\%)$ & $28(0.2)$ & $3(0.1)$ & 0 & 0 & $31(0.1)$ \\
\hline Not on Statin Therapy n (\%) & $511(2.7)$ & $139(6.1)$ & $150(100.0)$ & $155(7.5)$ & $955(4.1)$ \\
\hline
\end{tabular}

*High-intensity statins (atorvastatin 40-80 $\mathrm{mg}$ and rosuvastatin $20-40 \mathrm{mg}$ )

$\dagger$ Moderate-intensity statins (atorvastatin 10-20 mg, rosuvastatin 5-10 mg, simvastatin 20-40 mg, and pitavastatin 2-4 mg)

\$Low-intensity statins (simvastatin $10 \mathrm{mg}$ ).

$\S$ The 2060 patients who received statins after physician-patient dialogue included the following: Diabetic patients $>75$ years, diabetic patients with LDL $<70$ $\mathrm{mg} / \mathrm{dL}$, nondiabetic patients $>75$ years, nondiabetic patients with LDL $<70 \mathrm{mg} / \mathrm{dL}$, nondiabetic patients aged $40-75$ years with 10 -year ASCVD risk $<5 \%$ who were not on statins, nondiabetic patients aged 40-75 years with LDL 70-189 mg/dL who were receiving statin therapy because of a high ASCVD risk score or clinical discretion.

The 155 patients who did not receive statins after physician-patient dialogue included the following: Nondiabetic patients aged 4075 years with a 10 -year ASCVD risk $<5 \%, \mathrm{n}=133$; diabetic patients with $\mathrm{LDL}<70 \mathrm{mg} / \mathrm{dL}, \mathrm{n}=1$; diabetic patients with $\mathrm{LDL}<70 \mathrm{mg} / \mathrm{dL}$, n=2; nondiabetic patients with LDL $<70$ $\mathrm{mg} / \mathrm{dL}, \mathrm{n}=8$; and nondiabetic patients aged $>75$ years, $\mathrm{n}=11$.

Of the 2,290 patients $(9.8 \%)$ eligible for moderateintensity statins, $75.8 \%(n=1,735)$ were concordant with the guideline; however, $18.1 \%(\mathrm{n}=413)$ were over-treated with high-intensity statins and $6.1 \%(n=139)$ did not receive any statins. Overall, 2,060 patients were eligible for statins after shared discussion with physicians, of which 155 did not receive any statins.

\subsection{Concordance to Statin Therapy in the 4 Statin Benefit Groups}

Of the total 23,295 patients, $60.4 \%(n=14,070)$ patients with a history of clinical ASCVD were eligible for secondary prevention. Of these patients, 42.8\% $(n=6,027)$ received high-intensity statins, more than half $(55.0 \%, \mathrm{n}=7,732)$ received moderate-intensity statins, and 2.2\% $(n=303)$ did not receive any statin therapy. Of patients with ASCVD in the older age group $>75$ years $(n=566), 44.7 \%(n=253)$ were treated with high-intensity statins (Figure 1b). Interestingly, among the high-risk ASCVD patients receiving maximal intensity statins $(n=6,027)$, most patients $(98.9 \%, n=5962)$ had LDL-C $\geq 70 \mathrm{mg} / \mathrm{dL}$ (Figure 2a).

Among patients without clinical ASCVD $(n=7,122)$ who were eligible for primary prevention because of coexisting risk factors, 3.9\% $(\mathrm{n}=278)$ had LDL-C $\geq 190 \mathrm{mg} / \mathrm{dL}, 94.0 \%$ $(\mathrm{n}=6,694)$ had diabetes, and 2.1\% $(\mathrm{n}=150)$ patients had 10year ASCVD risk of $\geq 7.5 \%$. Of the diabetic patients having low ASCVD risk <7.5\% $\quad(n=1,681), \quad 85.5 \% \quad(n=1,438)$ received the apt moderate-intensity statins. However, among diabetic patients with high ASCVD risk $\geq 7.5 \% \quad(n=5,013)$, $82.9 \%(\mathrm{n}=4,157)$ remained under-treated with moderateintensity statins (Figure 1b). Similarly, most patients $(82.0 \%$, $\mathrm{n}=228$ ) with LDL-C $\geq 190 \quad \mathrm{mg} / \mathrm{dL} \quad$ ( $\mathrm{n}=278$ ) were inappropriately prescribed moderate-intensity statins (Figure 1b). About 2.1\% $(\mathrm{n}=150)$ patients with high ASCVD risk $\geq 7.5 \%$ eligible for primary prevention with moderate-high 
intensity statins were not receiving any statin therapy. Additionally, $\mathrm{n}=43$ patients with ASCVD risk 5\%-7.5\%, who were eligible for moderate-intensity statin therapy were not receiving any statins (data not shown).

Among the people in the high-risk group, the proportion of patients achieving an optimal LDL-C level of $<100 \mathrm{mg} / \mathrm{dL}$ was low despite receiving statin therapies of various intensities: high-intensity $18.6 \% \quad(n=1,199)$, moderateintensity $21.9 \%(\mathrm{n}=2590)$, and low-intensity $71.4 \%(\mathrm{n}=20)$ (Figure 2b). Very high LDL-C level $(\geq 190 \mathrm{mg} / \mathrm{dL})$ was present in $5.2 \%(n=338)$ patients receiving high-intensity statins and $5.3 \% \quad(\mathrm{n}=623)$ patients receiving moderateintensity statins.

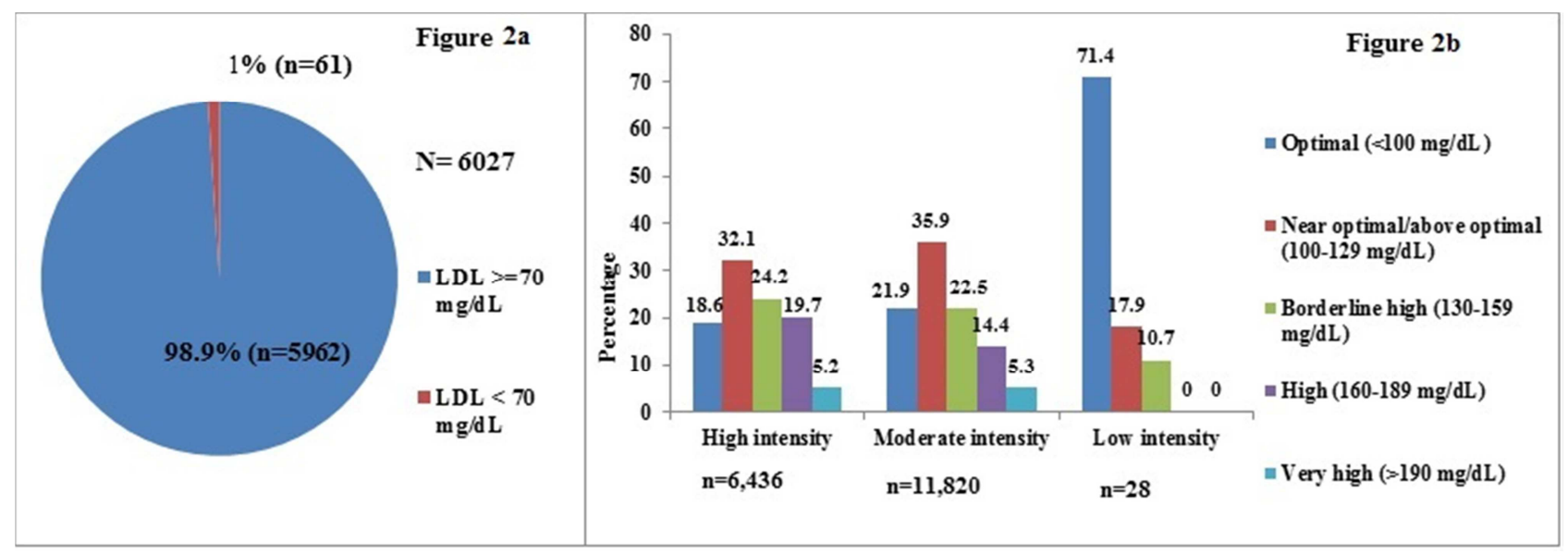

Figure 2. Distribution of $L D L-C$ levels of patients in the study population

a LDL-C levels of patients with clinical ASCVD receiving high-intensity statins. b LDL-C levels achieved in high-risk groups with various statin intensities. LDL-C: Low-density lipoprotein cholesterol.

\section{Discussion}

This nationally representative real-world study assessed the 10-year ASCVD risk among Indian patients and evaluated the concordance to 2013 ACC/AHA statin therapy guideline for the primary and secondary prevention of ASCVD.

Fewer than 5\% people achieve the 7 metrics of ideal cardiovascular health including regular exercise, no smoking, low saturated fats, TC $<200 \mathrm{mg} / \mathrm{dL}, \mathrm{BP}<120 / 80 \mathrm{mmHg}$, glucose $<100 \mathrm{mg} / \mathrm{dL}$, and BMI $<25 \mathrm{~kg} / \mathrm{m}^{2}$ [14]. Nearly onethird of our study population were tobacco users, half were obese, and three-fourths had diabetes and hypertension, whereas $46.3 \%$ had TC $\geq 200 \mathrm{mg} / \mathrm{dL}$. A cross-sectional study in India by Guptha et al demonstrated that the prevalence of $\mathrm{TC} \geq 200 \mathrm{mg} / \mathrm{dL}$ was $25.0 \%$ and that of triglycerides $\geq 150$ $\mathrm{mg} / \mathrm{dL}$ was $36.9 \%$ [15]. Heterogeneity in risk factors, accelerated build-up with an early age of onset, high fatality rate, and suboptimal treatment in lower socioeconomic strata, alongside low awareness and treatment of hypercholesterolemia are major concerns for ASCVD management in India [3, 6].

Maintaining optimal lipid levels is an important component of ideal cardiovascular health. Statins are the cornerstone for dyslipidemia management. About $12.6 \%$ of annual ASCVD deaths can be prevented if eligible people receive statin therapy [16]. However; physician adherence to dyslipidemia guidelines presents a crucial challenge [17]. Our study found major gaps in prescription practices for statin therapy; only one-third patients eligible for highintensity statins received treatment in concordant with guidelines. Most patients with ASCVD received moderateintensity statins while $2.2 \%$ did not receive any statins. A registry-based study from the United States revealed that in cardiovascular practice $32.4 \%$ of statin-eligible patients were not receiving the recommended therapy, and only $49.9 \%$ of ASCVD patients were receiving statin therapies [18]. Wander et al conducted a survey of 404 physicians across India and reported that high-intensity statins were preferred by $73.7 \%$ of physicians in post-acute coronary syndrome patients, while $50 \%$ doctors chose not to use statins in diabetic patients [19]. In our study, most diabetics with high ASCVD risk $\geq 7.5 \%(82.9 \%)$ remained under-treated. The India Heart Watch-2 study also revealed that statins are prescribed in only $55 \%$ of diabetes patients [9].

Our study results also highlight a possible gap in the dose titration and clinical inertia among physicians while prescribing statin therapy. Most patients taking low- or moderate-intensity statins were not titrated to a high dosage following an episode of ASCVD irrespective of their diabetes status, leaving residual risk for recurrent CVD events [20]. Lack of training, time constraints, complex guidelines, patient preferences, and perceived side effects are few reasons for suboptimal provider compliance to clinical guidelines [21, 22]. A physician survey in the United States revealed that $27.8 \%$ of physicians believed statins caused diabetes and $97.2 \%$ believed that statins cause myopathy [23]. A physician survey from Singapore reported that low awareness of standard guidelines, disagreement with 
guideline recommendations, and concerns about statin intolerance in Asians were the major impediments to guideline implementation [24]. However, the REAL-CAD trial in Japan showed that compared with low-intensity statins, high-intensity statins reduced MACE (major adverse cardiovascular events) with no added risk of serious adverse events [25]. A study from Singapore also demonstrated that the reduction in LDL-C by statins was not influenced by Asian ethnicity or BMI, suggesting that statin dosages should be titrated upward when target lipid levels are not achieved [26]. It is crucial to formulate strategies that increase physician awareness and enhance physician compliance for statin guidelines while accounting for issues like patient intolerability and cost-effectiveness. Distributing educational materials, conducting periodic audits, providing feedback and continuity of care, and establishing communication between distant healthcare professionals can enhance guideline adherent prescription of statins/lipid lowering agents (OR 1.23 ; 95\% CI 1.07-1.42, $\mathrm{p}=0.004$ ) among physicians [27].

The most effective strategy to prevent cardiovascular events would be to achieve optimal lipid levels early in life and maintain them throughout life, thus reducing exposure to cumulative LDL-C and slowing plaque progression [14]. Most ASCVD patients in our study receiving high-intensity statins had LDL $\geq 70 \mathrm{mg} / \mathrm{dL}$, highlighting a room for improvement in this population. Similar findings of persistent residual cholesterol risk have been demonstrated in PROVEIT, IMPROVE-IT, and VIRGO registry studies [28]. The 2018 ACC/AHA guideline recommends addition of nonstatins, such as ezetimibe, to maximally tolerated statin therapy in patients at very high ASCVD risk with LDL-C levels $\geq 70 \mathrm{mg} / \mathrm{dL}$. In patients with severe hypercholesterolemia, if LDL-C levels remain $\geq 100 \mathrm{mg} / \mathrm{dL}$, adding ezetimibe and consequently a PCSK9 inhibitor may be considered in addition to high- or moderate-intensity statins. However, a survey from India showed that only $30 \%$ doctors preferred ezetimibe in patients with uncontrolled LDL-C alongside a maximum-dose statin therapy, whereas $34 \%$ did not use ezetimibe in clinical practice [19].

The 2018 ACC/AHA guidelines recommend screening and management of adults above 20 years for dyslipidemia. A study from Kerala in India estimated that $61 \%$ of individuals aged 18 to 39 years had a high lifetime predicted risk of developing ASCVD [29]. The India Heart Watch-2 study demonstrated that statin prescriptions are lower in patients aged $<40$ years [9]. The MORE study primarily focused only on patients aged 40-79 years. Early risk assessment followed by timely implementation of primordial and primary prevention strategies can provide a window of opportunity to mitigate the burden of ASCVD. Early prevention by optimizing health behaviors such as smoking or physical activity and primary prevention among patients with dyslipidemia, hypertension, or diabetes must begin during adolescence and early adulthood. Furthermore, the implementation of guideline-adherent pharmacological interventions is vital for secondary and tertiary prevention to prevent the progression and development of additional CVD
[30]. The retrospective cross-sectional design of our study was a limitation to evaluate the long-term impact of statin therapies on dyslipidemia. Data on younger population aged $<40$ years, renal dysfunction, statin intolerance, and prescription of non-statin cholesterol-lowering drugs were missing. Additionally, the study did not collect information on socioeconomic status and statin therapy cost; therefore, we could not ascertain if patient income or insurance may have influenced clinicians' decision to prescribe highintensity statins. Nevertheless, our study is by far the largest real-world study in India assessing the ASCVD risk and evaluating concordance to the recommended statin therapy guidelines.

\section{Conclusion}

This large real-world study evaluated the concordance of statin therapy to the recommended guidelines among Indian population. Most patients were receiving statins at an inappropriate intensity, especially patients with diabetes. This reflects major gaps in the real-world practice of prescribing statins for the primary and secondary prevention of ASCVD. High LDL-C levels despite maximal intensity statins highlight the need for addition of non-statin cholesterollowering drugs. Regular monitoring and addressing insufficient response by dose titration or change in statin therapy is crucial for ASCVD management. Addressing care gaps and promoting compliance through enhanced physician awareness to optimize statin therapy will help prevent cardiovascular disease, especially in high-risk population among South Asians.

\section{Acknowledgements}

The authors thank all the physicians and doctors across India who kindly agreed to participate in the MORE study and extended their support for data collection. The authors thank Piyalee Pal (Covance Scientific Services \& Solutions Pvt. Ltd., Pune) for providing medical writing support for development of the manuscript. The authors also thank Garima Joshi (Covance Scientific Services \& Solutions Pvt. Ltd., Pune) for providing statistical support.

\section{References}

[1] World Health Organization. Cardiovascular diseases (CVDs) [Internet]. Geneva: World Health Organization; 2017 [cited April 2019]. Available from: https://www.who.int/cardiovascular_diseases/en/ files/7/en.html.

[2] Yusuf S, Rangarajan S, Teo K, et al. Cardiovascular risk and events in 17 low-, middle-, and high-income countries. $N$ Engl J Med 2014; 371 (9): 818-27.

[3] Prabhakaran D, Jeemon P, Roy A. Cardiovascular diseases in India: current epidemiology and future directions. Circulation 2016; 133 (16): 1605-20. 
[4] Prabhakaran D, Jeemon P, Sharma M, et al. The changing patterns of cardiovascular diseases and their risk factors in the states of India: the Global Burden of Disease Study 1990 2016. Lancet Glob Health 2018; 6 (12): 1339-51.

[5] Volgman AS, Palaniappan LS, Aggarwal NT, et al. Atherosclerotic cardiovascular disease in South Asians in the United States: epidemiology, risk factors, and treatments: a scientific statement from the American Heart Association. Circulation 2018; 138 (1): 1-34.

[6] Gupta R, Rao RS, Misra A, et al. Recent trends in epidemiology of dyslipidemias in India. Indian Heart $J$ 2017; 69 (3): 382-92.

[7] Vaduganathan M, Venkataramani AS, Bhatt DL. Moving Toward Global Primordial Prevention in Cardiovascular Disease: The Heart of the Matter. J Am Coll Cardiol 2015; 66 (14): 1535-7.

[8] Stone NJ, Robinson JG, Lichtenstein AH, et al. 2013 ACC/AHA guideline on the treatment of blood cholesterol to reduce atherosclerotic cardiovascular risk in adults: a report of the American College of Cardiology/American Heart Association Task Force on Practice Guidelines. J Am Coll Cardiol 2014; 63 (25 Part B): 2889-934.

[9] Gupta R, Lodha S, Sharma KK, et al. Evaluation of statin prescriptions in type 2 diabetes: India Heart Watch-2. BMJ Open Diabetes Res Care 2016; 4 (1): e000275.

[10] American Diabetes Association. Introduction: Standards of Medical Care in Diabetes-2018. Diabetes Care 2018; 41 (1): $1-\mathrm{S} 2$.

[11] Misra A, Chowbey P, Makkar BM, et al. Consensus statement for diagnosis of obesity, abdominal obesity and the metabolic syndrome for Asian Indians and recommendations for physical activity, medical and surgical management. $J$ Assoc Physicians India 2009; 57 (2): 163-70.

[12] Chobanian AV, Bakris GL, Black HR, et al. The seventh report of the joint national committee on prevention, detection, evaluation, and treatment of high blood pressure: the JNC 7 report. JAMA 2003; 289 (19): 2560-71.

[13] Lipsy RJ. The National Cholesterol Education Program Adult Treatment Panel III guidelines. J Manag Care Pharm 2003; 9 (1): $2-5$.

[14] Ference BA, Graham I, Tokgozoglu L, et al. Impact of Lipids on Cardiovascular Health: JACC Health Promotion Series. $J$ Am Coll Cardiol 2018; 72 (10): 1141-56.

[15] Guptha S, Gupta R, Deedwania P, et al. Cholesterol lipoproteins and prevalence of dyslipidemias in urban Asian Indians: A cross sectional study. Indian Heart J 2014; 66 (3): 280-8.

[16] Yang Q, Zhong Y, Gillespie C, et al. Assessing potential population impact of statin treatment for primary prevention of atherosclerotic cardiovascular diseases in the USA: population-based modelling study. BMJ Open 2017; 7 (1): e011684.

[17] Vashitz G, Meyer J, Parmet Y, et al. Physician adherence to the dyslipidemia guidelines is as challenging an issue as patient adherence. Fam Pract 2011; 28 (5): 524-31.
[18] Maddox TM, Borden WB, Tang F, et al. Implications of the 2013 ACC/AHA cholesterol guidelines for adults in contemporary cardiovascular practice: insights from the NCDR PINNACLE registry. J Am Coll Cardiol 2014; 64 (21): 2183-92.

[19] Wander GS, Jadhav UM, Chemburkar A, et al. Lipid management in India: a nationwide, cross-sectional physician survey. Lipids Health Dis 2017; 16 (1): 130.

[20] Giustino G, Colantonio LD, Brown TM, et al. Titration to high-intensity statin therapy following acute myocardial infarction in patients with and without diabetes mellitus. Cardiovasc Drugs Ther 2018; 32 (5): 453-61.

[21] Graham IM, Stewart M, Hertog MGL. Factors impeding the implementation of cardiovascular prevention guidelines: findings from a survey conducted by the European Society of Cardiology. Eur J Cardiovasc Prev Rehabil 2006; 13 (5): 839-45.

[22] Elisabeth AB, Denig P, van Vliet T, et al. Reasons of general practitioners for not prescribing lipid-lowering medication to patients with diabetes: a qualitative study. BMC Fam Pract 2009; 10 (1): 24.

[23] Clough JD, Martin SS, Navar AM, et al. Association of primary care providers' beliefs of statins for primary prevention and statin prescription. $J$ Am Heart Assoc 2019; 8 (3): e010241.

[24] Setia S, Fung SS, Waters DD. Doctors' knowledge, attitudes, and compliance with 2013 ACC/AHA guidelines for prevention of atherosclerotic cardiovascular disease in Singapore. Vasc Health Risk Manag 2015; 11: 303-10.

[25] Taguchi I, Iimuro S, Iwata H, et al. High-Dose Versus LowDose Pitavastatin in Japanese Patients With Stable Coronary Artery Disease (REAL-CAD): A Randomized Superiority Trial. Circulation 2018; 137 (19): 1997-2009.

[26] Tan CE, Loh LM, Tai ES. Do Singapore patients require lower doses of statins? The SGH Lipid Clinic experience. Singapore Med $J$ 2003; 44 (12): 635-8.

[27] Nguyen T, Nguyen HQ, Widyakusuma NN, et al. Enhancing prescribing of guideline-recommended medications for ischaemic heart diseases: a systematic review and metaanalysis of interventions targeted at healthcare professionals. BMJ Open 2018; 8 (1): e018271.

[28] Ridker Paul M. How Common Is Residual Inflammatory Risk? Circ Res. 2017; 120 (4): 617-9.

[29] Menon VP, Edathadathil F, Sathyapalan D, et al. Assessment of 2013 AHA/ACC ASCVD risk scores with behavioral characteristics of an urban cohort in India: Preliminary analysis of Noncommunicable disease Initiatives and Research at AMrita (NIRAM) study. Medicine 2016; 95 (49): e5542.

[30] Hong KN, Fuster V, Rosenson RS, et al. How Low to Go With Glucose, Cholesterol, and Blood Pressure in Primary Prevention of CVD. J Am Coll Cardiol 2017; 70 (17): 217185. 